\title{
Cognitive Behavior Therapy (CBT): An Effective Treatment for Major Depressive Disorders: A Case Study
}

\author{
Firdous Afzal $^{1 *}$, Dr. Haroon Rashid ${ }^{2}$, Dr. Syeda Razia Bukhari ${ }^{3}$
}

\section{ABSTRACT}

This study found cognitive behavior therapy as affective for treatment of depression of young adolescent girl due to breakup. Her treatment was carried out over 3 month period in a clinical routine setting of psychological clinic at Armed Forces Institute of Mental Health Rawalpindi. She suffered from severe hopelessness, low mood, isolation, lethargy, insomnia for few months. These symptoms have markedly disturbed her social, educational activities. For her treatment cognitive behavior techniques such as cognitive restructuring, psycho education, behavioral techniques, spiritual awareness, forgiveness and gratitude practice were used to treat her depression. Pre, post treatment and follow-up evaluations were established to check the severity level. A prominent change in her symptoms has been indicated which shows that Cognitive Behavior Therapy is an effective treatment for depression. Furthermore, full remission was maintained at 3 months follow-up.

Keywords: Major Depressive Disorder (Hopelessness, Isolation, Lethargy, Low Mood), Cognitive Behavior Therapy

Depression is a disorder of certain length, sign and symptoms that markedly interfere with a person's functioning and causes high personal distress. Depression is not like everyday sadness and grief of loved ones, because people with blues or grief may have symptoms of depression but they functions normally. But when a person is suffering from depression he must need treatment to continue with life because depressive disorder affects one mood, thinking, bodily functions and behaviors (Griest \& Jefferson, 1992). Research findings shows that Cognitive behavior therapy is an effective treatment for depression. The standard 12-session CBT has been found efficacious for clinically significant change in depression symptoms (Chafey et al. 2009; Embling. 2002). CBT operates on its theory to produce change in thought process of client which

\footnotetext{
${ }^{1}$ Clinical Psychologist, National Institute of Psychology, Quaid-e-Azam University Islamabad, Pakistan

${ }^{2}$ Senior Clinical Psychologist, Armed Forces Institute of Mental health, Rawalpindi, Pakistan

${ }^{3}$ Clinical Psychologist, National Institute of Psychology, Quaid-e-Azam University Islamabad, Pakistan *Responding Author
}

Received: January 3, 2017; Revision Received: February 10, 2017; Accepted: February 15, 2017

(C) 2017 Afzal F, Rashid H, Bukhari S; licensee IJIP. This is an Open Access Research distributed under the terms of the Creative Commons Attribution License (www.creativecommons.org/licenses/by/2.0), which permits unrestricted use, distribution, and reproduction in any Medium, provided the original work is properly cited. 


\section{Cognitive Behavior Therapy (CBT): An Effective Treatment for Major Depressive Disorders: A Case Study}

in turn produce relief from depressive symptoms and lowered chances of relapse (Driessen \& Hollon. 2010). Cognition is the basic component of cognitive behavior therapy, as it determines our feelings and behaviors, so by modifying dysfunctional negative thought by mean of cognitive behavioral strategies, one can produce positive change in dysfunctional thoughts, emotions and behaviors.

\section{CASE REPORT}

The patient was 18 years old, first year student, unmarried girl, last-born, having two brothers from a middle socioeconomic status Muslim family living in a nuclear family setup in Rawalpindi. The patient was facing serious difficulty in studies and in interpersonal relationship with family and friends. Her family reported that she stayed alone, isolated. She could not perform her daily activities, she feel lethargy most of the time and did not take care of herself. Patient reported that she has crying spell often, and she could not sleep at night and feel emptiness. She said that she is hopeless about her future and found no meaning in life. The patient had started facing these complaints for long time but now these disturbances had subjugated her social and educational life and she wanted to get treatment for it. Patient was sexually abuse in childhood, she blame herself for it and have guilt over it. She was then again sexually abuse in adolescent age two times; these events had put her in depression. After these incidents she then had a romantic relationship with a boy for two years. She used to share her grief with him and had spent good time with him. But after two years of relation, the boy stared ignoring her gradually and finally broke up with her which had again put her in depression. She felt unable to continue life without him and spent her time by remembering time spent with him. She sometime feels sexual urges and could not control herself. She never told her parents about her disturbance. She thought that why had this happened to her, what was her fault. Her mother did not pay attention to her and patient longs for her affection. Her father is supportive, but he does not have time to spend with her. Her brothers are also busy in their own life, and she feels alone at home and longs for someone who can listen to her problems. Patient was sexually abuse in childhood and then in teenage. Sexual abuse at different time of life had severely disturbed the clients and developed guilt over abuse, and negative thinking, sexual urges, strong desire for intimacy, high need for protection and nurturance. She feels alone at home and longs for someone who can listen to her problems. She had good friends in school and effective relationship with teachers. But transition to college life was a stressor for her, she was unhappy with her career choice that is made by her father, and was unhappy with college teachers and class fellows which further supported her depressive behaviors.

\section{ASSESSMENT \& DIAGNOSIS}

Patient's formal and informal clinical assessment is conducted at Armed Forces Institute of Mental Health by means of standard psycho-diagnostic tools: clinical intake form, Human Figure Drawing test (HFD), Thematic Apperception Test (TAT), and Rorsarch Inkblot test. DSM5 


\section{Cognitive Behavior Therapy (CBT): An Effective Treatment for Major Depressive Disorders: A Case Study}

severity measure for depression was used to measure severity of depression before and after the treatment. The pretest subjective reporting and scale score indicated moderate level of depression.

\section{DSM-5 CASE FORMULATION}

Presenting complaints: She presented following symptoms: isolation, hopelessness, low mood, low appetite, lethargy, insomnia, poor concentrations, crying for few months. On the basis of DSM- 5 she is diagnosed with major depressive disorder moderate level. Predisposing factor: patient has weak immune system and poor physical health; she has low self esteem, a high need for nurturance, dependency. She has coping deficits because of painful affective experiences. She has passive, immature, impulsive introvert personality. She also had suffered childhood sexual abuse. All these bio-psycho-social factors predisposed her to depressive symptoms and low self worth. As Meta analysis of clinical studies indicated that sexual abuse in childhood increases the chances of psychiatric disorders in later adult life (Chen et al., 2010). Sexual abuse in childhood is correlated with emotional issues later in life. Abused child may develop later in life symptoms of depression, isolation, poor self esteem, and feeling of guilt, shame, self blame, negative thinking, sexual and relationship problems (Browne et al. 1986; Hartman et al. 1987; Hall \& Hall. 2011). Precipitating event: The event that triggered her symptoms was her breakup with lover who left her after a two years romantic relationship, which put her into isolation, and markedly disturbed her social, interpersonal and educational life. Perpetuating factor: the patient recurrent symptoms of isolation, hopelessness and negative thinking patterns are maintaining her depression. Protective factor: patient is willing to take psychotherapy and accepts responsibility to change. Her strengths which can help in her recovery are higher level of developmental functioning; bright cognition and Intellectualism, Creativity, and Artistic talent.

\section{TREATMENT}

The patient was treated using CBT manual for depression (Rossello \& Bernal., 2007). Patient had given the consent to participate in research. Patient was introduced with therapy which is based on the interrelationship of thoughts, actions and feelings, and helped adolescent to gain control of feelings. Therapy sessions were divided into three topics, each topic consisting of four sessions. In first four sessions work was done on how thoughts influence mood. The next four sessions focuses on daily activities that affect mood. The last four sessions put emphasis on how our interactions with others affect our mood.

In first sessions patient was introduced with what is depression and how it affects our thoughts. Therapist also defined the type of thoughts which helped patient to realize her own thinking patterns. In next three sessions therapist helped client to identify her dysfunctional thoughts and change them with more positive thoughts. During each session week, patient was asked to fill mood thermometer, she was also given home assignment to keep daily log of her negative thought, and replace them with more positive thoughts. She was encouraged to develop positive

(C) The International Journal of Indian Psychology, ISSN 2348-5396 (e)| ISSN: 2349-3429 (p) | 82 


\section{Cognitive Behavior Therapy (CBT): An Effective Treatment for Major Depressive Disorders: A Case Study}

thinking by replacing negative thoughts of guilt and hopelessness through asking God's forgiveness and gratitude practice which in turn helped her to gain hope and positivity back in life. At the end of $4^{\text {th }}$ session, Client developed insight about her symptoms, and an understanding of her own negative thoughts. By spiritual awareness she gained hope back in life and by asking forgiveness of God, practicing gratitude she removed her guilt feeling and found peace in her life. With this improvement she become motivated and fully accepted the responsibility for changing her depressive behaviors. In next 5-8 sessions her activity level is increased by planning her daily activities and assigning her task to follow the activity plan. She is helped to realize that it is her rigid and demanding thought ("I can't live without him"; "nobody loves me", "people should understand my problem"). She realized it and accepted to replace these thoughts with more positive and helpful thoughts. Patient was encouraged to increase pleasant experiences to improve her low mood and lethargy. Home work assignments including weekly planner, setting specific goals and completing them were given. She started exercising, walking, and talking with family members, with these improvements her isolation, low mood has subsided and she had good sleep in these weeks.

In last 9-12 sessions she was taught how our relationship affects our mood. She was taught to build social relations and support system in effective way. Assertive training and role playing were used to improve her social communication and relationship. At the end of treatment she was symptom free, and had learned skills to deal with stress and day to day problems. She was symptom free at follow-up session after a period of 3 months.

The table shows raw score or composite scores for pre post test and 4 months follow up.

\begin{tabular}{|l|l|l|l|l|}
\hline Depression & Pre-test scores & Post-test scores & Pre-Post Difference & Follow up scores \\
\hline $\begin{array}{l}\text { Severity } \\
\begin{array}{l}\text { Measure for } \\
\text { Depression }\end{array}\end{array}$ & 3 & 15 & 4 \\
\hline
\end{tabular}

\section{OUTCOME \& IMPLICATION}

CBT manual for depression was used for period of three months which involved one session per week. Outcome of treatment showed significant decrease in depressive symptoms. Therapist observation, patient subjective, objective reporting and parents reporting showed that patient has gained positive change in her behavior. Pre treatment score was 18(moderate depression), while post treatment score were 3 (normal depression) on DSM5 depression severity measure scale for depression.

The present study suggests that sexual abuse in childhood followed by teenage abuse predispose young girls to depression and an unusual increase in sexual interest and intimacy. Individual may develop romantic relationship in order to deal with their emotional distress of trauma. Sex 


\section{Cognitive Behavior Therapy (CBT): An Effective Treatment for Major Depressive Disorders: A Case Study}

education and understanding of one's changing emotions should be provided to young girls so they can regulate their emotions properly.

\section{Acknowledgments}

The author appreciates all those who participated in the study and helped to facilitate the research process.

Conflict of Interests: The author declared no conflict of interests.

\section{REFERENCES}

American psychiatric Association. (2013a). Diagnostic and statistical manual of mental disorders (5th ed.). Washington DC: American Psychiatric Association.

American psychiatric Association. (2014). Online assessment measures. Retrieved from http://www.psychiatry.org/practice/dsm/dsm5/online-assessment-measures.

American psychiatric Association.(2013). Diagnostic and Statistical Manual of Mental Disorders. (5th ed.). Washington, DC.

Chafey, M. J., Bernal,G., \& Rossello, J. (2009). Clinical Case study for Depression in a Puetro

Chen, L.P., Murad, M.H., Paras, M.L., Colbenson, K.M., Sattler, A. L., Goranson, E. N., Elamin, M.B., Seime,R.J., Shinozaki, G., Prokop, L. J., Zirakzadeh, A. (2010). Sexual abuse and life time diagnosis of psychiatric disorders: Systematic review and meta-analysis. Mayo Clinic Proceedings, 85(7), 618-629. DOI: 10.4065/mcp.2009.0583

Driessen, D., \& Hollon,S.D.(2010). Cognitive behavioral therapy for mood disorders: efficacy, moderators and mediators. Psychiatr Clin North Am. 33(3): 537-555 doi:10.1016/j.psc.2010.04.005.

Exner, John E. (2002). The Rorschach: Basic Foundations and Principles of Interpretation. NJ: John Wiley \& Sons, Hoboken.

Griest, J.H., \& Jefferson, J. W. (1992). Depression and its treatment. American psychiatric Press. Inc.

Hall, M., \& Hall, J. (2011). The long term effects of childhood sexual abuse: Counseling Implications. Retrieved from http://counselingoutfitters.com/vistas/vistas11/Article_19.pdf

Hartman,M., Finn,S., \& Leon, G. (1987). Sexual abuse experiences in a clinical population: Comparison of familial and non familial abuse. Psychotherapy: Theory, Research, Practice, Training. 24(2), 154-159

Koppitz, E.M. (1967). Psychological evaluation of children’s human figure drawings: New York. London.

Psychological Bulletin, 99(1), 66-77 http://dx.doi.org/10.1037/0033-2909.99.1.66

Rican Adolescent: Challenges and Variability in Treatment Response. Depression And Anxiety. 26:98-103 


\section{Cognitive Behavior Therapy (CBT): An Effective Treatment for Major Depressive Disorders: \\ A Case Study}

Rossello,J., \& Bernal,G. (2007). Treatment Manual for Cognitive Behavioral Therapy for Depression: Adaptation for Puerto Rican Adolescents. Retrieved from: http://ipsi.uprrp.edu/pdf/manuales_tara/group_manual_eng.pdf

Sharf. S. R.(2010). Theories of psychotherapy and counseling: Concepts and Cases, Cenage Learning.

How to cite this article: Afzal F, Rashid H, Bukhari S (2017), Cognitive Behavior Therapy (CBT): An Effective Treatment for Major Depressive Disorders: A Case Study, International Journal of Indian Psychology, Volume 4, Issue 2, No. 89, ISSN:2348-5396 (e), ISSN:2349-3429 (p), DIP:18.01.088/20170402, ISBN:978-1-365-74162-3 